\title{
Pome and Stone Fruits: Safe Handling Practices for Consumers $^{1}$
}

Amy Simonne ${ }^{2}$

Eating a variety of fruits and vegetables is part of a healthy diet. However, care must be taken to avoid any contamination during the preparation process, as some foodborne illnesses have been traced to fresh produce. Pome and stone fruits come from fruit trees grown in temperate zones. Pome and stone fruits include pears, apples, apricots, sweet cherries, nectarines, peaches, and plums. Here are steps that you can take to reduce your risk of foodborne illness from fresh produce.

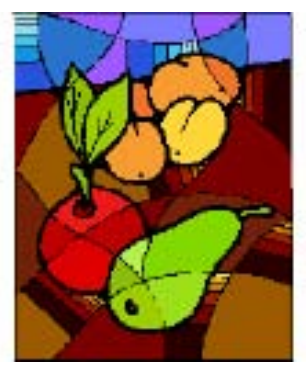

\section{Where You Shop:}

Buy only undamaged pome and stone fruits that are free of bruises.

Fresh-cut fruit should be refrigerated or surrounded by ice.

\section{At Home:}

Refrigerate ripe pome and stone fruits promptly. For optimum flavor, some stone fruits such as peaches can be left at room temperature to ripen before storing in the refrigerator.

Refrigerate fresh cut fruit within two hours of peeling or cutting.

Discard leftover cut fruit after two hours at room temperature.

\section{During Preparation:}

Wash hands with hot soapy water before and after:

- handling fresh produce

- handling raw meat, poultry, or seafood

- using the bathroom

- changing diapers

- handling pets

Wash pome and stone fruits with cool tap water just before preparing or eating. Don't use soap or detergents.

Peel the fruit if possible to reduce surface contamination.

1. This publication is FCS8742, one of a series of the Department of Family, Youth and Community Sciences, Florida Cooperative Extension Service, Institute of Food and Agricultural Sciences, University of Florida. First published: November 2002. Reviewed: March 2006. Please visit the EDIS Web site at http://edis.ifas.ufl.edu

2. Amy Simonne, Ph.D., associate professor, Department of Family, Youth, and Community Sciences, Institute of Food and Agricultural Sciences, University of Florida, Gainesville FL 32611.

The Institute of Food and Agricultural Sciences (IFAS) is an Equal Employment Opportunity-Affirmative Action Employer authorized to provide research, educational information and other services only to individuals and institutions that function without regard to race, creed, color, religion, age, disability, sexual orientation, marital status, national origin, political opinions, or affiliation. For information on obtaining other extension publications, contact your county Cooperative Extension Service office. Florida Cooperative Extension Service/Institute of Food and Agricultural 
Scrub firm fruit with a clean produce brush. Rinse with cool tap water.

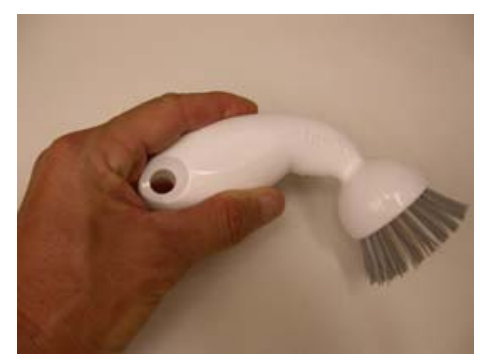

Remove core from apples and pears and rinse well before cutting. This will reduce potential contamination of microbes from the inner core materials.

Cut away bruised or damaged areas before preparing or eating.

Wash cutting boards, dishes, utensils, and counter tops often. Use hot soapy water and rinse well. Sanitize them after contact with fresh produce, or raw meat, poultry, or seafood (see box).

Sanitize kitchen sink, counter tops and other food contact surfaces often to prevent a build up of microbes.

Don't cross contaminate! Use clean cutting boards and utensils for fresh produce.

If you can, use separate cutting boards for raw meat, poultry, and seafood.

Do not consume ice that has come in contact with fresh produce or other raw products.

Use a cooler with ice or ice gel packs when you take perishable foods outdoors. This includes cut fresh fruits and vegetables.
To sanitize cutting boards, dishes, and utensils:

Mix one teaspoon chlorine bleach in one quart water.

Pour the mixture onto all surfaces or submerge appropriate items into the above solution and let sit at least one minute.

Rinse surfaces well with hot running water.

Counter tops can be sanitized by using the above solution mix, sanitizing sprays or wipes as an additional safety measure.

A dishwasher with hot water cycle (at least $180^{\circ} \mathrm{F}$ or $82^{\circ} \mathrm{C}$ ) for a final rinse is also effective.

Following these steps will help reduce your risk of foodborne illness from fresh produce.

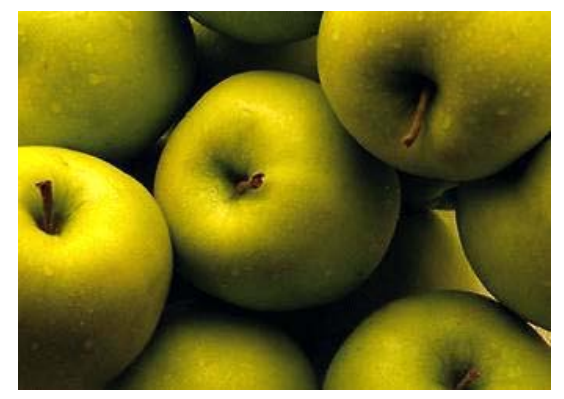

\section{For More Information:}

Visit the Food and Drug Administration (FDA) website at: http://www.fda.gov or call FDA Consumer Inquiries at 1-888-SAFEFOOD (a tollfree number). 